\title{
Construction of a Derivative of Agrobacterium tumefaciens C58 That Does Not Mutate to Tetracycline Resistance
}

\author{
Zhao-Qing Luo, ${ }^{1}$ Thomas E. Clemente, ${ }^{3}$ and Stephen K. Farrand ${ }^{1,2}$ \\ Departments of ${ }^{1}$ Crop Sciences and ${ }^{2}$ Microbiology, University of Illinois at Urbana-Champaign, Urbana \\ 61801, U.S.A.; ${ }^{3}$ Center for Biotechnology, University of Nebraska, Lincoln 68588, U.S.A. \\ Accepted 17 September 2000.
}

\begin{abstract}
Agrobacterium tumefaciens C58 mutates to tetracycline resistance at high frequency, complicating the use of many broad-host-range cloning and binary vectors that code for resistance to this antibiotic as the selection marker. Such mutations are associated with a resistant gene unit, tet $_{\mathrm{C} 58}$, that is present in the genome of this strain. By deleting the tet $_{\mathrm{C58}}$ locus, we constructed NTL4, a derivative of C58 that no longer mutates to tetracycline resistance. The deletion had no detectable effect on genetic or physiological traits of NTL4 or on the ability of this strain to transform plants.
\end{abstract}

Additional keywords: genetic engineering.

Agrobacterium tumefaciens strain C58 and its derivatives such as Ti plasmid-cured strains NT1 (Waston et al. 1975), A136 (Waston et al. 1975), and C58C1 (Van Larebeke et al. 1974) are used in many genetic and molecular analyses of Agrobacterium spp. and their plasmids. Such emphasis is largely a result of several useful traits or properties of this biovar 1 strain, including transformability (Cangelosi et al. 1991; Holsters et al. 1978), the availability of auxotrophic mutants, genetic (Hooykaas et al. 1982; Miller et al. 1986) and physical maps (Goodner et al. 1999) of the chromosomes (Allardet-Servent et al. 1993), a well-characterized recA mutant (Farrand et al. 1989), and cosmid clone banks (Farrand et al. 1989; Luo and Farrand 1999). Furthermore, some properties of the C58 chromosomal background may condition virulence on certain plant species that are recalcitrant to other $A$. tumefaciens strains. For example, the Ti plasmid pTiBo542 (Hood et al. 1986; Komari et al. 1986) in its cognate chromosomal background confers moderate virulence. However, this plasmid confers hypervirulence on many plants, including important crops such as soybean, when present in the C58 chromosomal background (Hood et al. 1986). Because of this enhanced virulence, derivatives of C58 containing pEHA101 (Hood et al. 1986) and pEHA105 (Hood et al. 1993), disarmed vir helper plasmids derived from pTiBo542, are widely used

Corresponding author: S. K. Farrand; Telephone: +1-217-333-1524; Fax: +1-217-244-7830; E-mail: stephenf@uiuc.edu as binary plant transformation agents.

C58 and its derivatives give rise to tetracycline-resistant mutants at a high frequency (Luo and Farrand 1999). Such mutants arise because of a latent tetracycline resistance determinant, tet $_{\mathrm{C} 58}$, which is located on one of the chromosomes of C58 and its derivatives (Luo and Farrand 1999). This resistance unit consists of two genes, tet $_{\mathrm{C} 58}$, which apparently codes for an efflux pump that confers the resistance, and tet $R_{\mathrm{C} 58}$, which encodes a repressor that inhibits the expression of $t e t A_{\mathrm{C} 58}$ (Luo and Farrand 1999). Mutations in the repressor (which is not responsive to the antibiotic) can result in strains that express constitutive resistance to high levels of tetracycline. Such mutations pose problems because many broadhost-range vectors used in the genetic and molecular analysis of Agrobacterium spp. utilize tetracycline resistance as the selection marker. Such selections must be performed with caution, and using this antibiotic to maintain the plasmid entails a high risk of selecting for tetracycline-resistant mutants that can lose the plasmid of interest.

We report here the construction of a C58 derivative with a precise internal deletion of a portion of $t_{e} t_{\mathrm{C} 58}$. We used a twostep deletion-allele exchange procedure in which the resultant strain has not acquired additional resistance markers and does not mutate to tetracycline resistance. We also show that deleting tet $_{\mathrm{C} 58}$ has no other detectable physiological or genetic effects on this bacterium and does not affect the ability of the strain to transform plants.

To construct an internal deletion in the tet $_{\mathrm{C} 58}$ locus, we first cloned an approximately 8.0-kb EcoRI fragment (corrected from 8.5) (Luo and Farrand 1999) that contains the wild-type tet $_{\mathrm{C} 58}$ region from pZLE8.5 into pSW213 (Table 1) to generate pSWE8.5. Because the multiple cloning site (MCS) region of the vector is flanked by two EcoRI sites, the cloning removed all of the other recognition sites in the polylinker, allowing us to delete an internal portion of the $\operatorname{tet}_{\mathrm{C} 58}$ locus by restriction enzyme digestion. The tet $_{\mathrm{C} 58}$ locus was disrupted by digesting pSWE8.5 with HindIII and KpnI that cut at the $3^{\prime}$ end of tet $R_{\mathrm{C} 58}$ and within the $5^{\prime}$ region of $t e t A_{\mathrm{C} 58}$, respectively (Luo and Farrand 1999). Digested DNA was blunted with mung bean nuclease and religated, and the clones were recovered by $\mathrm{CaCl}_{2}$-mediated transformation (Sambrook et al. 1989) into Escherichia coli DH5 $\alpha$ (Table 1). In the resultant clone, 
pSWE7, the treatment removed almost all of tet $R_{\mathrm{C} 58}$, the $5^{\prime}$ one-fifth of $t e t A_{\mathrm{C} 58}$, and the entire promoter control region located between the two divergently expressed genes. As predicted from the DNA sequence of the tet $_{\mathrm{C} 58}$ locus (Luo and Farrand 1999), after digestion with EcoRI, the insert size in pSWE7 is about $1 \mathrm{~kb}$ shorter than that of the wild type (data not shown). In addition, each side of the $\Delta$ tet $_{\mathrm{C} 58}$ locus is flanked by about $3 \mathrm{~kb}$ of C58 genomic DNA (Fig. 1), which is sufficient to allow allele replacement by homologous recombination.

The vector component of pSWE7, pSW213, codes for resistance to tetracycline (Table 1), which necessitates the recloning of the $\Delta$ tet $_{\mathrm{C} 58}$ fragment to a vector suitable for further experiments. The IncP1 $\alpha$ vector, pRK415K (Table 1), contains three SmaI sites, one in the MCS region and two in its own tet $t_{\mathrm{RP} 4}$ gene unit (Cook and Farrand 1992; Keen et al. 1988). Purified pRK415K, which also contains the lacZ $\alpha$ gene, was partially digested with $S m a \mathrm{I}$, religated, and transformed into $E$. coli $\mathrm{DH} 5 \alpha$. Blue colonies on agar plates containing 5-bromo-4-chloro-3-indolyl- $\beta$-D-galactopyranoside and kanamycin were picked and screened for sensitivity to tetracycline. One such colony containing pRK415KTc ${ }^{-}$was retained for further analysis. The removal of the SmaI fragment containing the tet $_{\mathrm{RP} 4}$ gene unit from the vector was confirmed by restriction endonuclease analysis of this plasmid (data not shown). The 7.0-kb EcoRI fragment containing $\Delta$ tet $_{\mathrm{C} 58}$ from pSWE7 was cloned into $\mathrm{pRK} 415 \mathrm{KTc}^{-}$to give pZLE7. This plasmid and pZLE8.5, which carries the intact tet $_{\mathrm{C} 58}$ locus, were independently introduced into E. coli $\mathrm{DH} 5 \alpha$. Neither plasmid conferred tetracycline resistance on this enteric host. However, while DH5 $\alpha$ (pZLE8.5) gave rise to tetracycline-resistant variants, the strain harboring pZLE7 failed to produce such mutants at a detectable level $\left(<10^{-8}\right)$ (data not shown).

Plasmid pZLE7 was used in a two-step strategy to introduce the deleted tet $_{\mathrm{C} 58}$ locus into the chromosome of $A$. tumefaciens NT1. The method is similar to that used by Jones et al. (1988) to construct a tra-deletion derivative of the agrocin 84 plasmid, pAgK84. First, pZLE7 was cointegrated by homologous recombination into the chromosome of NT1 (Table 1 and Fig. 1). This was achieved by mobilizing pZLE7 from E. coli S171(pZLE7) into NT1TcR1, a spontaneous tetracycline-resistant mutant of NT1 (Table 1) (Luo and Farrand 1999), producing NT1TcR1(pZLE7). To select for derivatives of NT1TcR1 that contain the cointegrated form of pZLE7, another IncP plasmid, pPH1JI (Hirsch and Beringer 1984), encoding a gentamicin resistance marker, was mated into NT1TcR1(pZLE7) from E. coli 2174. Colonies resistant to kanamycin, tetracycline, and gentamicin were selected, and one such transconjugant, NT1TcR1KG (Table 1), was retained for further use. To allow the second recombination event that resolves the cointegrate by deleting the $\operatorname{tet}_{\mathrm{C} 58}$ locus (Fig. 1), NT1TcR1KG was grown in Luria-Bertani (LB) broth (Sambrook et al. 1989) with gentamicin as the only selection. After four subcultures, a portion of the culture was plated onto nutrient agar (NA) (Difco, Detroit, MI, U.S.A.) at a dilution giving about 150 to 200 colo-

Table 1. Bacterial strains and plasmids used in this study

\begin{tabular}{|c|c|c|}
\hline Strain or plasmid & Relevant characteristic(s) ${ }^{a}$ & Source and reference \\
\hline \multicolumn{3}{|l|}{ Escherichia coli } \\
\hline DH5 $\alpha$ & $\begin{array}{l}\mathrm{F}^{-} \phi 80 \mathrm{~d} l a c Z \Delta \mathrm{M} 15 \text { endA1 recA1 hsdR17 }\left(\mathrm{r}_{\mathrm{K}}{ }^{-} \mathrm{m}_{\mathrm{K}}{ }^{+}\right) \text {supE44 thi-1 gyrA96 } \Delta \text { (lacZYA-argF) } \\
\mathrm{U} 169\end{array}$ & Sambrook et al. 1989 \\
\hline S17-1 & Pro $^{-}$Res $^{-}$Mod $^{+}$recA; integrated RP4-Tet::Mu-Kan::Tn 7, Mob $^{+}$ & Simon et al. 1983 \\
\hline 2174(pPH1JI) & Met Pro $\mathrm{Gm}^{\mathrm{r}} \mathrm{Sp}^{\mathrm{r}}$ used to evict IncP plasmids & Hirsch and Beringer 1984 \\
\hline \multicolumn{3}{|c|}{ Agrobacterium tumefaciens } \\
\hline NT1 & pTiC58-cured derivative of strain C58 & Waston et al. 1975 \\
\hline NT1TcR1 & Randomly chosen tetracycline-resistant mutant of NT1; tet $R_{\mathrm{C} 58}:: \mathrm{IS} 426, \mathrm{Tc}^{\mathrm{r}}$ & Luo and Farrand 1999 \\
\hline NT1TcR1GK & $\begin{array}{l}\text { Derivative of NT1TcR1 into which pZLE7 is cointegrated at the } t^{2} t_{\mathrm{C} 58} \text { locus; } \mathrm{Tc}^{\mathrm{r}}, \mathrm{Gm}^{\mathrm{r}} \text {, } \\
\mathrm{Km}^{\mathrm{r}}\end{array}$ & This study \\
\hline NTL4 & Derivative of NT1 with an internal deletion of the $t t_{\mathrm{C} 58}$ locus, $_{\text {N }} \Delta t t_{\mathrm{C} 58}, \mathrm{Tc}^{\mathrm{s}}$ & This study \\
\hline \multicolumn{3}{|c|}{ - } \\
\hline pRK415 & Broad-host-range cloning vector; IncP1 $\alpha$, lacZ $\alpha, \mathrm{Tc}^{\mathrm{r}}$ & Keen et al. 1988 \\
\hline pRK415K & Kanamycin-resistant derivative of pRK415; IncP1 $\alpha$, lacZ $\alpha, \mathrm{Tc}^{\mathrm{r}}, \mathrm{Km}^{\mathrm{r}}$ & Cook et al. 1993 \\
\hline $\mathrm{pRK} 415 \mathrm{KTc}^{-}$ & $\begin{array}{l}\text { Derivative of pRK415K with an internal deletion of the tetracycline resistance cassette; } \\
\mathrm{Km}^{\mathrm{r}}\end{array}$ & This study \\
\hline pSW213 & Broad-host-range cloning vector; IncP, $\mathrm{Tc}^{\mathrm{r}}$ & Chen et al. 1994 \\
\hline pPH1JI & IncP1 R plasmid used to evict IncP vectors; $\mathrm{Gm}^{\mathrm{r}}$ & Hirsch and Beringer 1984 \\
\hline pZLE8.5 & $\begin{array}{l}\text { 8.0-kb EcoRI fragment containing the wild-type } t t_{\mathrm{C} 58} \text { locus cloned into pBluescript } \\
\mathrm{SK}(+), \mathrm{Ap}^{\mathrm{r}}\end{array}$ & Luo and Farrand 1999 \\
\hline pZLOP1 & $\begin{array}{l}\text { 66-bp tet } \mathrm{C}_{58} \text { intergenic region cloned into promoter reporter vector } \mathrm{pRG} 970 \mathrm{~b} \text {; IncP/ColE1, } \\
\mathrm{Ap}^{\mathrm{r}}, \mathrm{Sm}^{\mathrm{r}} / \mathrm{Sp}^{\mathrm{r}}\end{array}$ & Luo and Farrand 1999 \\
\hline pDLB4 & $\begin{array}{l}\text { Broad-host-range expression vector containing } \operatorname{araC} \text { and the } \mathrm{P}_{\mathrm{BAD}} \text { promoter; unknown Inc } \\
\text { group, } \mathrm{Km}^{\mathrm{r}}\end{array}$ & Luo and Farrand 1999 \\
\hline pDLB4-tetR & $\begin{array}{l}\text { tetR } R_{\mathrm{C} 58} \text { cloned into pDLB4 as a } 2.7-\mathrm{kb} N c o \text { I fragment; expression of } t e t R_{\mathrm{C} 58} \text { from } \mathrm{P}_{\mathrm{BAD}} \text { is } \\
\text { controlled by AraC and arabinose }\end{array}$ & Luo and Farrand 1999 \\
\hline pSWE8.5 & 8.0-kb EcoRI fragment containing wild-type tet $_{\mathrm{C} 58}$ from pZLE8.5 cloned into pSW213 & This study \\
\hline pSWE7 & Derivative of pSWE8.5 with an approximately $1-\mathrm{kb}$ deletion within tet $_{\mathrm{C} 58}$ & This study \\
\hline pZLE7 & 7.0-kb EcoRI DNA fragment containing $\Delta t_{t e t}{ }_{\mathrm{C58}}$ from $\mathrm{pSWE7}$ cloned into $\mathrm{pRK} 415 \mathrm{KTc}^{-}$ & This study \\
\hline pZP212 & $\begin{array}{l}\text { Binary vector encoding } n p t I I \text { driven by the } 35 \mathrm{~S} \text { promoter of Cauliflower mosaic virus; } \\
\text { IncP/ColE } 1, \mathrm{Sm}^{\mathrm{r}} / \mathrm{Sp}^{\mathrm{r}}, \mathrm{Cm}^{\mathrm{r}}\end{array}$ & Hajdukiewicz et al. 1994 \\
\hline pEHA105 & vir helper plasmid derived from pTiBo542 & Hood et al. 1993 \\
\hline
\end{tabular}

${ }^{a} \mathrm{Ap}^{\mathrm{r}}=$ ampicillin resistant, $\mathrm{Cm}^{\mathrm{r}}=$ chloramphenicol resistant, $\mathrm{Gm}^{\mathrm{r}}=$ gentamicin resistant, $\mathrm{Km}^{\mathrm{r}}=$ kanamycin resistant, $\mathrm{Sm}^{\mathrm{r}} / \mathrm{Sp}^{\mathrm{r}}=\mathrm{streptomy}$ cin/spectinomycin resistant, $\mathrm{Tc}^{\mathrm{r}}=$ tetracycline resistant, and $\mathrm{Tc}^{\mathrm{s}}=$ tetracycline sensitive. 
nies per plate. The resultant colonies were patched individually onto NA and NA containing $2 \mu \mathrm{g}$ of tetracycline per milliliter. A single tetracycline-sensitive clone was identified among the first 300 colonies screened. This isolate was cured of pPH1JI by growing the strain for several subcultures in L broth without antibiotic selection. One colony that was susceptible to tetracycline and gentamicin was recovered from this culture regimen and named $A$. tumefaciens NTL4.

We confirmed the deletion-mutation by Southern analysis. The approximately 8.0-kb EcoRI fragment containing tet $_{\mathrm{C} 58}$ was used to probe EcoRI-digested chromosomal DNA of NT1, NT1TcR1, two colonies of NTL4, and preparations of pSWE8.5 and pSWE7. The probe hybridized with an approximately $8.0-\mathrm{kb}$ fragment in the digest of NT1, which is consistent with the size of the fragment carried on pSWE8.5 (Fig. 2). Furthermore, two fragments, one about $4.5 \mathrm{~kb}$ and the other about $4.9 \mathrm{~kb}$, were detected in the digest of NT1TcR1 (Fig. 2). These results are in agreement with our DNA sequence analysis of the tet $_{\mathrm{C} 58}$ locus in this mutant (Luo and Farrand 1999). The tet $R_{\mathrm{C} 58}$ gene of this isolate was disrupted by IS426, which introduced an EcoRI site into the repressor gene and divided this locus into two EcoRI fragments. Both of these fragments were absent in genomic DNA from two colonies of NTL4, being replaced by a single band of approximately $7.0 \mathrm{~kb}$ that matched the size of the insert carrying the deletion allele present on pSWE7 (Fig. 2).

We examined the response of this new strain to tetracycline and several other antibiotics. Approximately $5 \times 10^{9}$ cells from saturated cultures of NT1 and NTL4 in LB broth were inoculated onto plates of NA and ABM agar minimal medium (Chilton et al. 1974) containing 1, 2, 5, and $10 \mu \mathrm{g}$ of tetracycline per milliliter. Similar volumes of NTL4 were plated onto media containing kanamycin or gentamicin. While wild-type NT1 yielded several thousand colonies after $72 \mathrm{~h}$ on plates containing all concentrations of tetracycline, NTL4 gave no colonies on any of these plates, even after $120 \mathrm{~h}$ of incubation at $28^{\circ} \mathrm{C}$ (Fig. 3 and data not shown). Furthermore, as with the wild-type strain, NTL4 is susceptible to kanamycin and gentamicin (data not shown). Analysis of plasmid DNA from this strain by a mini-prep procedure (Hayman and Farrand 1988) did not detect any plasmids less than $450 \mathrm{~kb}$ (data not shown), indicating that the strain was cured of the eviction plasmid pPH1JI. NTL4 retains pAtC58, the 450-kb santhopinecatabolic plasmid present in C58 (Vaudequin-Dransart et al.

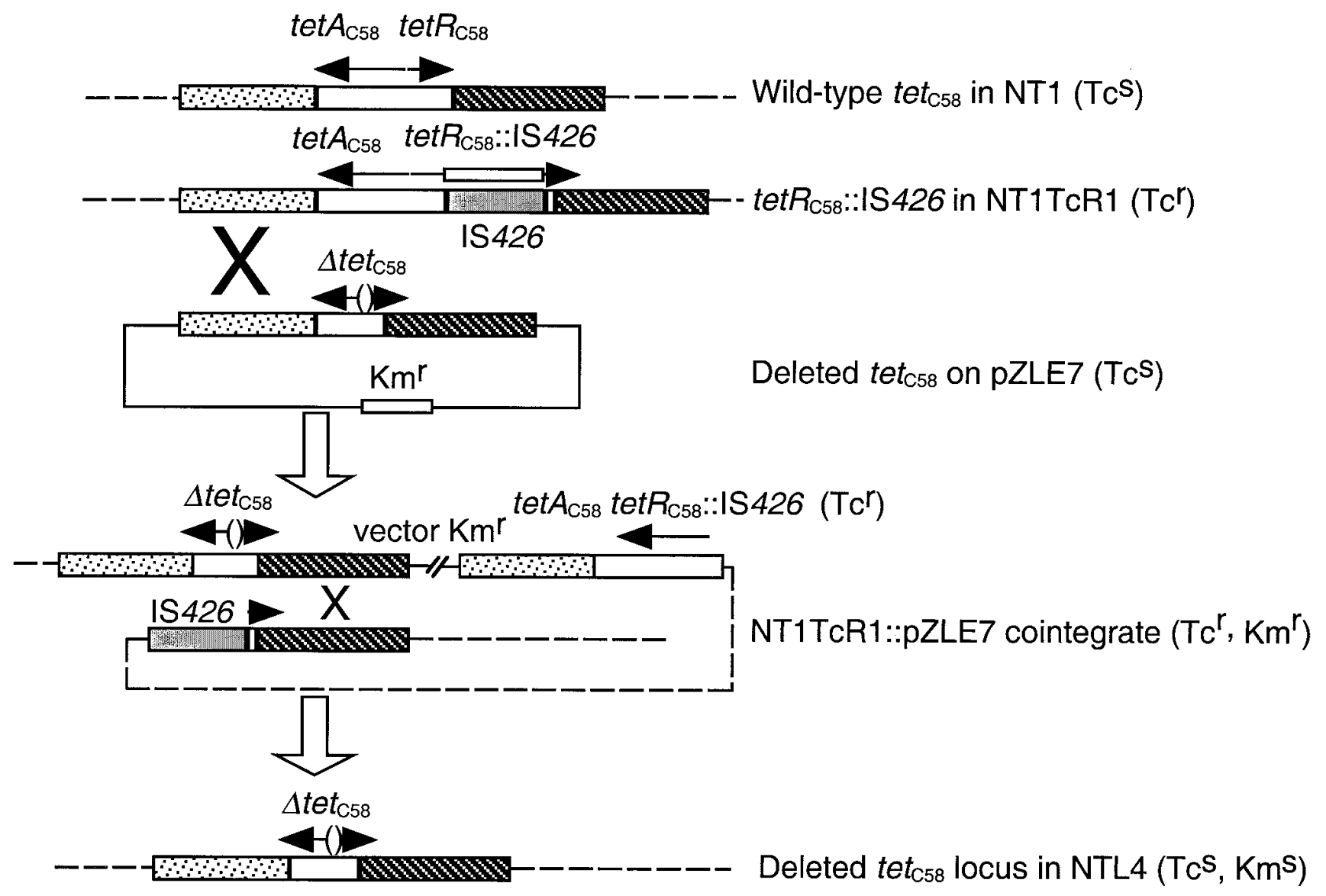

Fig. 1. Construction of Agrobacterium tumefaciens strain NTL4. Structures of the tet $_{\text {C58 }}$ locus in strains NT1, NT1TcR1, NT1TcR1::ZLE7, and NTL4 are shown. The first crossover (large X) between pZLE7 and the $t^{2 t} t_{\mathrm{C} 58}$ locus in NT1TcR1 led to the duplication of the flanking sequences of the $t t_{\mathrm{C} 58}$ locus and generation of strain NT1TcR1::ZLE7, which is resistant to tetracycline and kanamycin. The second recombination event occurring between one of the duplicated regions (small X) resulted in the resolution of the cointegrate by excision of the vector region of pZLE7 and deletion of the tet $t_{\text {C58::IS426 }}$ locus. Recombination events leading to the deletion are shown occurring first on the left side of $t e t_{\mathrm{C} 58}$ to form the cointegrate and then on the right side to resolve the cointegrate, but they could have occurred in reverse order. Flanking sequences of C58 genomic DNA on both sides of tet $t_{\mathrm{C} 58}$ (open box) and IS426 (gray box) are shown as stippled and cross-hatched boxes. Vector DNA of pZLE7 and the chromosomal region far beyond tet ${ }_{\mathrm{C} 58}$ are solid lines and dashed lines, respectively. Arrows $=t e t A_{\mathrm{C} 58}, t e t R_{\mathrm{C} 58}$, or truncated $t e t R_{\mathrm{C} 58}$. Arrows separated by parenthesis $=$ deleted form of the $t e t_{\mathrm{C} 58}$ locus. 
1998). We conclude from these results that NTL4 lacks a functional $t e t A_{\mathrm{C} 58}$ gene.

Given the size and location of the deletion, NTL4 should not encode an active Tet $\mathrm{R}_{\mathrm{C} 58}$ protein. To test this hypothesis, we introduced into the new strain pZLOP1 a construct that contains the bidirectional promoter region of $t t_{\mathrm{C} 58}$, driving the expression of two divergently oriented reporter genes, uidA and lacZ (Table 1) (Luo and Farrand 1999). Expression of the reporter fusions was determined by measuring the activities of $\beta$-galactosidase $\quad\left(\right.$ tet $A_{\mathrm{C} 58}:$ :lacZ) and $\beta$-glucuronidase (tet $R_{\mathrm{C} 58}:$ :uidA), as described previously (Luo and Farrand 1999). Expression levels of both reporters in NTL4 were significantly higher than those observed in NT1(pZLOP1), which

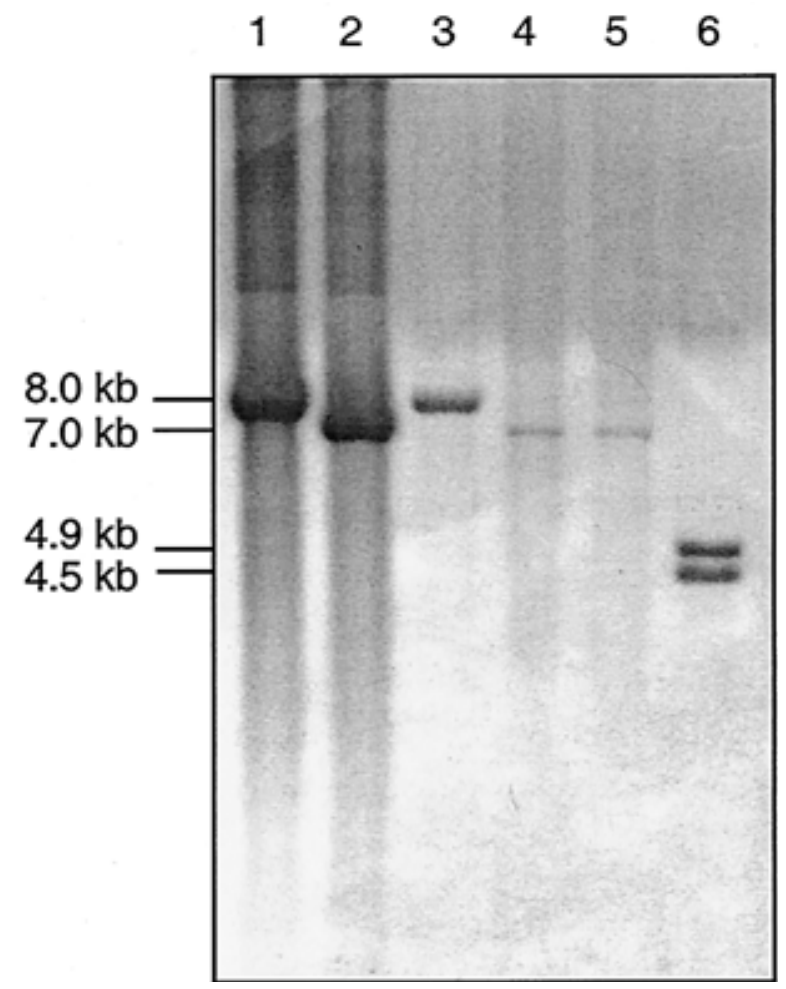

Fig. 2. Southern analysis of the tet $_{\mathrm{C} 58}$ locus of NTL4. Plasmid DNA and total genomic DNA were digested with EcoRI, and the fragments were separated by electrophoresis in an $0.8 \%$ agarose gel and transferred onto a nitrocellulose membrane. The 8.0-kb EcoRI fragment containing the tet $_{\mathrm{C} 58}$ locus labeled with dioxygenin was used as the probe. Hybridization, washing, and detection were conducted as previously described (Luo and Farrand 1999). Lanes: 1, pSWE8.5; 2, pSWE7, and digested genomic DNA from lanes 3 , NT1; 4, NTL4 colony $1 ; 5$, NTL4 colony 2; and $6, \mathrm{NT} 1 \mathrm{TcR} 1$. is tet $_{\mathrm{C} 58}{ }^{+}$, and approached the levels observed in the tet $R_{\mathrm{C} 58}:$ :IS426 strain, NT1TcR1(pZLOP1) (Table 2). Furthermore, when a functional $t e t R_{\mathrm{C} 58}$ gene coded for by pDLB4tetR (Table 1) was supplied in trans in NTL4(pZLOP1), the expression of the two reporter fusions was repressed (Table 2). These results indicate that the product of the disrupted $t e t R_{\mathrm{C} 58}$ gene in NTL4 no longer represses the tet $_{\mathrm{C} 58}$ operator.

As assessed by an increase in culture turbidity (Piper and Farrand 2000), NTL4 and NT1 grow with indistinguishable kinetics and to the same final population sizes in LB medium and ABM minimal medium (data not shown). Similarly, the time of development, size, morphology, consistency, and color of the colonies of the two strains are indistinguishable on NA and ABM agar medium (data not shown). Furthermore, plasmid DNA can be transformed, electroporated, or mated into NTL4 with the same efficiency as NT1 (data not shown).

To assess whether disruption of tet $_{\mathrm{C} 58}$ affects plant transformation activity of NTL4, we introduced the vir helper

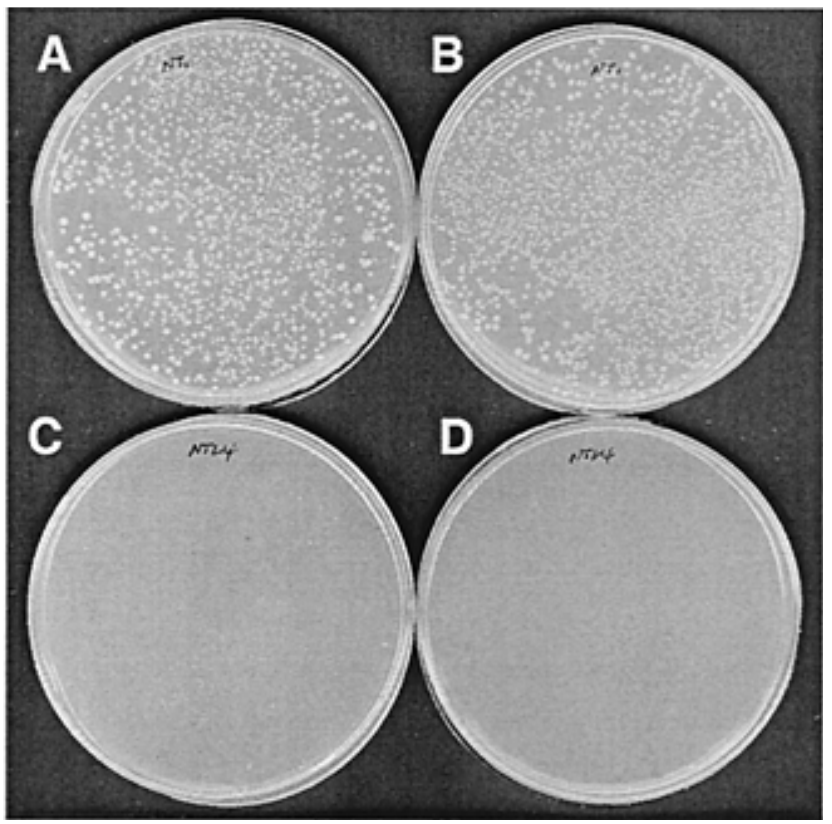

Fig. 3. NTL4 no longer mutates to tetracycline resistance. A and B, Strains NT1; C and D, NTL4 were grown to saturation in Luria-Bertani broth. Volumes of $200 \mu \mathrm{l}$ of the cultures (approximately $10^{9} \mathrm{CFU}$ ) were plated onto nutrient agar containing tetracycline at concentrations of 2 (A) and 5 (B and D) $\mu \mathrm{g} / \mathrm{ml}$. Emergence of mutants resistant to the antibiotic was judged by the appearance of colonies on the plates after incubation at $28^{\circ} \mathrm{C}$ for $72 \mathrm{~h}$. No colonies appeared on plates inoculated with NTL4, even after $120 \mathrm{~h}$ of incubation.

Table 2. The genome of NTL4 does not contain a functional $t e t R_{\mathrm{C} 58}$

\begin{tabular}{|c|c|c|c|c|c|}
\hline \multirow[b]{2}{*}{ Strain } & \multirow[b]{2}{*}{ tet $R_{\mathrm{C} 58}$ source or allele } & \multicolumn{2}{|c|}{$\beta$-Galactosidase activity $\left(\right.$ tet $A::$ lacZ $^{\mathrm{a}}$} & \multicolumn{2}{|c|}{$\beta$-Glucuronidase activity (tetR::uidA) } \\
\hline & & $-\mathbf{A r a}^{\mathbf{b}}$ & $+\mathbf{A r a}^{c}$ & -Ara & + Ara \\
\hline NT1(pZLOP1, pDLB4) & Chromosome & 19 & 14 & 14 & 20 \\
\hline NT1(pZLOP1, pDLB4-tetR) & Chromosome, pDLB4-tetR & 25 & 2 & 14 & 7 \\
\hline NT1TcR1(pZLOP1, pDLB4) & $\operatorname{tet} R:: \mathrm{IS} 426$ & 77 & 75 & 53 & 45 \\
\hline NTL4(pZLOP1, pDLB4) & None & 74 & 73 & 50 & 45 \\
\hline NTL4(pZLOP1, pDLB4-tetR) & pDLB4-tetR & 63 & 2 & 17 & 5 \\
\hline
\end{tabular}

a $\beta$-Galactosidase and $\beta$-glucuronidase activities are expressed as units per $10^{9} \mathrm{CFU}$ as previously described (Luo and Farrand 1999). The experiment was repeated twice with similar patterns of activities.

${ }^{\mathrm{b}}$ Results without arabinose (Ara).

${ }^{c}$ Ara was added at a final concentration of $0.4 \%$ to induce expression of $t e t R_{\mathrm{C} 58}$ from pDLB4-tetR. 
plasmid pEHA105 (Hood et al. 1993) into this strain as well as NT1 by electroporation (Cangelosi et al. 1991), selecting for utilization of mannopine. A binary vector, pZP212 (Hajdukiewicz et al. 1994), which codes for a plant-expressing nptII gene, was introduced into these NTL4 constructs, and the resultant strains were used to transform Nicotiana tabacum cv. Xanthi (TC533, North Carolina State University, Raleigh, U.S.A.) with a modified leaf-dip protocol (Horsch et al. 1985). Following cocultivation with the bacteria, plant leaf segments were transferred to regeneration medium composed of Murashige and Skoogs medium with B5 vitamins (MS-B5) (Manandhar and Gresshoff 1980) supplemented, per milliliter, with $1 \mu \mathrm{g}$ of 1,2-bis(2-amino-5-bromophenoxy)ethane$N, N, N^{\prime}, N^{\prime}$-tetraacetic acid (BAP), $0.1 \mu \mathrm{g}$ of naphthalene acetic acid (NAA), and $150 \mu \mathrm{g}$ of kanamycin. The explants were subcultured on the same medium every 2 weeks. The percentages of leaf disks with differentiating kanamycin-resistant shoots that arose following infection by the three clones of NTL4(pEHA105, pZP212) were indistinguishable from the percentages of explants giving shoots following infection with NT1(pEHA105, pZP212) (data not shown). Uninoculated explants cultured on the same medium were completely bleached after 4 weeks in culture (data not shown). A selected subset of kanamycin-tolerant shoots were excised after 6 to 8 weeks in culture and were rooted on an MS-B5-based medium supplemented, per milliliter, with $0.1 \mu \mathrm{g}$ of NAA and 50 $\mu \mathrm{g}$ of kanamycin. The shoots induced by NTL4 (pEHA105, pZP212) regenerated roots with frequencies indistinguishable to those of shoots induced by NT1 that harbored the same binary system (data not shown). A subset of transgenic plants transformed with each strain were established in soil, and plants were assayed for NptII protein content with a commercially available enzyme-linked immunosorbent assay kit ( $5^{\prime}$ to 3', Boulder, CO, U.S.A.), following the manufacturer's protocol. As shown in Table 3, all of the transgenic plants contained comparable levels of the NptII protein.

We also compared NTL4(pEHA105, pZP212) with its parent for using their ability to transform Arabidopsis thaliana with an in planta transformation protocol (Bechtold et al. 1993). The two strains yielded essentially the same numbers of antibiotic-resistant germinants when seeds from infected plants were plated onto selection medium containing kanamycin (data not shown). The results from these two sets of experiments indicate that the deletion in $t t_{\mathrm{C} 58}$ has no detectable effect on the plant transformation properties of this A. tumefaciens strain.

In summary, we have constructed a derivative of NT1 that contains an internal deletion of the tet $_{\mathrm{C} 58}$ locus. The strain, which no longer mutates to resistance to this antibiotic $\left(<10^{9}\right)$, simplifies the use of tetracycline resistance as a selection marker in the C58 genomic background. The two-step dele-

Table 3. Plants transformed by NTL4 exhibit NptII activity

\begin{tabular}{lcc}
\hline Transforming strain & N $^{\mathbf{a}}$ & NptII $^{\mathbf{b}}$ \\
\hline NT1(pEHA105, pZP212) & 6 & $37.9 \pm 17.6$ \\
NTL4(pEHA105, pZP212)-1 & 5 & $35.0 \pm 1.03$ \\
NTL4(pEHA105, pZP212)-2 & 3 & $33.2 \pm 12.4$ \\
NTL4(pEHA105, pZP212)-3 & 5 & $16.7 \pm 15.5$ \\
\hline
\end{tabular}

a The number of regenerated transgenic plants assayed.

${ }^{b}$ The mean of NptII expressed as picograms of protein per milligram of total protein per plant \pm standard deviation. tion-allele exchange strategy did not introduce any additional markers, and NTL4 remains susceptible to all antibiotics to which NT1 is sensitive. Moreover, because no tetracyclineresistant mutants arise, and it is entirely effective at low concentrations, we routinely use $2 \mu \mathrm{g}$ of this antibiotic per milliliter in rich and minimal media when required for genetic selection. In our use of this strain over the past 2 years, we have not observed any physiological alterations attendant to this mutation. Furthermore, the ability of NTL4 to transform the two plant species tested is indistinguishable from that of its parent strain, NT1.

\section{ACKNOWLEDGMENTS}

This study was supported by grants from the NIH (R01 GM52465) and the North Central Soybean Association (NC CNTRL SOY SKF ANTC) to S. K. Farrand.

\section{LITERATURE CITED}

Allardet-Servent, A., Michaux-Charachon, S., Jumas-Bilak, E., Karayan, L., and Ramuz, M. 1993. Presence of one linear and one circular chromosome in the Agrobacterium tumefaciens C58 genome. J. Bacteriol. 175:7869-7874.

Bechtold, N., Ellis, J., and Pelletier, G. 1993. In planta Agrobacterium mediated gene transfer by infiltration of adult Arabidopsis thaliana plants. C. R. Acad. Sci. Paris Life Sci. 316:1194-1199.

Cangelosi, G. A., Best, E. A., Marinetti, G., and Nester, E. W. 1991. Genetic analysis of Agrobacterium. Methods Enzymol. 204:384-397.

Chen, C. V., and Winans, S. C. 1994. Controlled expression of the transcriptional activator gene virG in Agrobacterium tumefaciens by using the Escherichia coli lac promoter. J. Bacteriol. 173:1139-1144.

Chilton, M.-D., Currier, T. C., Farrand, S. K., Bendich, A. J., Gordon, M. P., and Nester, E. W. 1974. Agrobacterium tumefaciens DNA and PS8 bacteriophage DNA not detected in crown gall tumors. Proc. Natl. Acad. Sci. USA 71:3672-3676.

Cook, D. M., and Farrand, S. K. 1992. The oriT region of the Agrobacterium tumefaciens Ti plasmid pTiC58 shares DNA sequence identity with the transfer origins of RSF1010 and RK2/RP4 and with T-region borders. J. Bacteriol. 174:6238-6246.

Farrand, S. K., O’Morchoe, S. P., and McCutchan, J. 1989. Construction of an Agrobacterium tumefaciens C58 recA mutant. J. Bacteriol. 171:5314-5321.

Goodner, B. W., Markelz, B. P., Flanagan, M. C., Crowell, C. B., Jr., Racette, J. L., Schilling, B. A., Halfon, E. M., Mellors, J. S., and Grabowski, G. 1999. Combined genetic and physical map of the complex genome of Agrobacterium tumefaciens. J. Bacteriol. 181:51605166.

Hajdukiewicz, P., Svab, Z., and Maliga, P. 1994. The small, versatile pPZP family of Agrobacterium binary vectors for plant transformation. Plant Mol. Biol. 25:989-994.

Hayman, G. T., and Farrand, S. K. 1988. Characterization and mapping of the agrocinopine-agrocin 84 locus on the nopaline Ti plasmid pTiC58. J. Bacteriol. 170:1759-1767.

Hirsch, P. R., and Beringer, J. E. 1984. A physical map of pPH1JI and pJB4JI. Plasmid 12:139-141.

Holsters, M., de Waele, D., Depicker, A., Messens, E., van Montagu, M., and Schell, J. 1978. Transfection and transformation of Agrobacterium tumefaciens. Mol. Gen. Genet. 163:181-187.

Hood, E. E., Gelvin, S. B., Melchers, L. S., and Hoekema, A. 1993. New Agrobacterium helper plasmids for gene transfer to plants. Transgenic Res. 2:208-218.

Hood, E. E., Helmer, G. L., Fraley, R. T., and Chilton, M.-D. 1986. The hypervirulence of Agrobacterium tumefaciens A281 is encoded in a region of pTiBo542 outside of T-DNA. J. Bacteriol. 168:1291-1301.

Hooykaas, P. J., Peerbolte, J. R., Regensburg, A. J. G., de Vries, P., and Schilperoort, R. A. 1982. A chromosomal linkage map of Agrobacterium tumefaciens and a comparison with the maps of Rhizobium spp. Mol. Gen. Genet. 188:12-17.

Horsch, R. B., Fry, J. E., Hoffmann, N. L., Eichholtz, D., Rogers, S. G., 
and Fraley, R. T. 1985. A simple and general method for transferring genes into plants. Science 227:1229-1231.

Jones, D. A., Ryder, M. H., Clare, B. G., Farrand, S. K., and Kerr, A. 1988. Construction of a $\mathrm{Tra}^{-}$deletion mutant of pAgK84 to safeguard the biological control of crown gall. Mol. Gen. Genet. 212:207-214.

Keen, N. T., Tamaki, S., Kobayashi, D., and Trollinger, D. 1988. Improved broad-host-range plasmids for DNA cloning in gram-negative bacteria. Gene 70:191-197.

Komari, T., Halperin, W., and Nester, E. W. 1986. Physical and functional map of supervirulent Agrobacterium tumefaciens tumorinducing plasmid pTiBo542. J. Bacteriol. 166:88-94.

Luo, Z.-Q., and Farrand, S. K. 1999. Cloning and characterization of a tetracycline resistance determinant present in Agrobacterium tumefaciens C58. J. Bacteriol. 181:618-626.

Manandhar, A., and Gresshoff, P. M. 1980. Blue spruce (Picea pungens) tissue and cell culture. Cytobios 129:175-182.

Miller, I. S., Fox, D., Saeed, N., Porland, P. A., Miles, C., and Sastry, G. R. 1986. Enlarged map of Agrobacterium tumefaciens C58 and the location of chromosomal regions which affect tumorigenecity. Mol. Gen. Genet. 205:153-159.
Piper, K. R., and Farrand, S. K. 2000. Quorum sensing but not autoinduction of Ti plasmid conjugal transfer requires control by the opine regulon and the antiactivator TraM. J. Bacteriol. 182:1080-1088.

Sambrook, J., Fritsch, E. F., and Maniatis, T. A. 1989. Molecular Cloning: A Laboratory Manual. 2nd ed. Cold Spring Harbor Laboratory, Cold Spring Harbor, NY, U.S.A.

Simon, R., Priefer, U., and Pühler, A. 1983. A broad host range mobilization system for in vivo genetic engineering: Transposon mutagenesis in gram-negative bacteria. Bio/Technology. 1:784-791.

Van Larebeke, N., Engler, G., Holsters, M., Van den Elsacker, S., Zaenen, I., Schilperoort, R. A., and Schell, J. 1974. Large plasmid in Agrobacterium tumefaciens essential for crown gall inducing ability. Nature (Lond.) 252:169-170.

Vaudequin-Dransart, V., Petit, A., Chilton, W. S., and Dessaux, Y. 1999. The cryptic plasmid of Agrobacterium tumefaciens cointegrates with the Ti plasmid and cooperates for opine degradation. Mol. PlantMicrobe Interact. 11:583-591.

Waston, B., Currier, T. C., Gordon, M. P., Chilton, M.-D., and Nester, E. W. 1975. Plasmid required for virulence of Agrobacterium tumefaciens. J. Bacteriol. 123:255-264. 